\title{
Are European white butterflies aposematic?
}

\author{
ANNE LYYTINEN*, RAUNO V. ALATALO, LEENA LINDSTRÖM \\ and JOHANNA MAPPES \\ Department of Biological and Environmental Science, University of Jyväskylä, \\ Jyväskylä, Finland \\ (*author for correspondence, tel.: +358 14260 4197; fax: + 35814260 2321; \\ e-mail: alyytine@dodo.jyu.fi)
}

Received 31 May 2000; accepted 27 October 2000

Co-ordinating editor: C. Rowe

\begin{abstract}
It has been suggested that the white coloration of Pieridae butterflies is a warning signal and therefore all white Pieridae could profit from a mimetic resemblance. We tested whether greenveined white (Pieris napi) and orange-tip (Anthocharis cardamines) butterflies benefit from white coloration. We compared their relative acceptability to wild, adult pied flycatchers (Ficedula hypoleuca) by offering live $A$. cardamines and $P$. napi together with two non-aposematic butterflies on the tray attached to birds' nesting boxes. Experienced predators equally attacked white and nonwhite butterflies, and the order of attack among the Pieridae was random. If anything, there was a slight indication that the female $A$. cardamines was the least favoured prey. Since birds did not avoid white coloration, we compared the palatability of these two species against known palatable and unpalatable butterflies by presenting them to great tits (Parus major). Pieris brassicae, which has been earlier described as unpalatable, was also included in the palatability test. However, there were no significant differences in the palatability of the butterflies to birds, and even $P$. brassicae was apparently palatable to the great tits. Our results do not unambiguously support the hypothesis that the white coloration of Pieridae would signal unpalatability. Nevertheless, in our last experiment, pied flycatchers often rejected or left untouched free flying $P$. napi and $A$. cardamines. This suggests that other features in a more natural situation, such as the agile flight pattern or odours might still make them unprofitable to birds.
\end{abstract}

Key words: Anthocharis cardamines, aposematism, Lepidoptera, palatability, Pieridae, Pieris brassicae, P. napi

\section{Introduction}

It has been suggested that butterflies from the Pieridae family are aposematic with their yellow or white coloration (e.g. Jones, 1932; Kettlewell, 1965). It has also been hypothesised that they constitute a Müllerian mimicry group, in which Pieris brassicae, starting the flight period earliest and being the most unpalatable among the family, would act as the model (Marsh and Rothschild, 1974). Marsh and Rothschild (1974) tested palatabilities indirectly by injecting Pieridae extracts directly into a mouse muscle. However, their experiment has 
been criticised since there is a possibility that any general foreign-protein reaction might cause mouse morbidity and mortality (Ley and Watt, 1989). Additionally, recent feeding studies have suggested that $P$. napi is edible at least to some degree, but is not favoured prey (Kingsolver, 1987; Ley and Watt, 1989; but see Lane, 1957). It has even been proposed that Anthocharis cardamines is a Batesian mimic (Marttila et al., 1990). Taken together, these data suggest that Pieridae butterflies exhibit a spectrum of palatability, as Brower (1984) concluded in his review. Thus, it is still unclear whether Pieridae butterflies could be regarded as palatable or unpalatable, and whether they are aposematic or even mimetic.

Here we present the results of series of experiments conducted to test the acceptability and palatability of adult $P$. napi and A. cardamines. Besides belonging to the Pieridae family, these species have at least three common features. First, their green caterpillars live solitarily on their food plant. They feed on many plant species of Brassicaceae that contain mustard oil glycosides as secondary plant metabolites, which might render the butterfly unpalatable (Aplin et al., 1975). Second, their flight periods and distributions in Finland are overlapping. Butterflies emerge in May, but the flight season ends at a different time in the summer. Anthocharis cardamines flies until the end of June whilst $P$. napi can be seen even at the beginning of September. Both of them fly in open habitats. Pieris napi is one of the most common butterflies in Finland, while A. cardamines is less numerous and occurs mainly in southern and central Finland. Finally, the adults have wings with a white upper side and a wingspan of the same size ( $P$. napi: $32-47$ and $A$. cardamines: $29-48 \mathrm{~mm}$ ). The white coloration is conspicuous in flight and could easily serve as a warning signal. However, the male $A$. cardamines have orange-coloured tips on the forewings making them distinctive from any other white butterflies. Thus, females of the same species are more easily confused with $P$. napi in flight than are the males.

In this paper we gave pied flycatchers (Ficedula hypoleuca) a choice between $P$. napi and A. cardamines and recorded the order in which they were eaten. If the white coloration has a function as an aposematic signal, experienced birds should avoid white butterflies in a preference test. We were also interested in whether female $A$. cardamines benefit by resembling P. napi. We also tested their palatability using great tits (Parus major) as predators. Since visual cues might influence the behaviour of the birds, visual recognition was made impossible in the palatability test. Thus we were able to evaluate whether the birds found white butterflies unpalatable. Finally, in a more natural test of predator responses, we tested whether free-flying $P$. napi and $A$. cardamines are differentially predated or can even escape avian predation in outdoor cages. 


\section{Material and methods}

\section{Preference experiment}

The work was performed with the pied flycatcher (Ficedula hypoleuca) around the Konnevesi Research Station in central Finland, in June 1999. We chose pied flycatchers as predators, because flying insects constitute roughly $20 \%$ of their diet in Finland (Alatalo and Alatalo, 1979). We estimated the comparative acceptability of $P$. napi and $A$. cardamines to pied flycatchers $(n=20)$ by presenting a set of butterflies collected from natural populations.

Before the start of the experiment, the birds were familiarised with the tray that was to be used in the experiment by offering mealworms in a cup on the tray attached to birds' nesting boxes. In this way the birds were used to seeing the tray and thus did not hesitate to visit their nesting box during the experiment.

We attached one of each sex of $P$. napi and $A$. cardamines by gluing the ventral tips of the wings on the brown tray. Thus, only the appearance of the butterfly could affect the prey choice. To ensure that the birds readily attacked the butterflies, two palatable sympatric species, one individual of northern wall brown (Lasiommata petropolitana) and one pearl-bordered fritillary (Clossiana euphrosyne), were also glued onto the same tray. The tray was placed in an upright position at a pied flycatcher's nesting box, and observed through binoculars. We ranked the order (from 1 to 6) that birds took each butterfly, and if birds left any butterfly untouched it received the order value of seven. If a colour has an aposematic function it could be expected that wild, experienced birds would avoid the colour. The order of consumption of butterflies thus reflects the preference differences.

To ensure that only one individual visited the nest during the experiment, one of the parent birds was captured and removed before each experiment. The experiment was terminated after the bird had consumed all the butterflies or had not even touched the remaining butterflies and had lost interest in them. The captured bird was released back into the vicinity of the nest immediately after the experiment. On the following day, the experiment was conducted on the other parent of the same nest with a new set of butterflies.

\section{Test for palatability in the laboratory}

Since the preference experiment did not indicate any avoidance of Pieridae butterflies, we also tested whether birds found them unpalatable. In this experiment we used great tits (Parus major) instead of pied flycatchers. Pied flycatchers rapidly swallow butterflies whole, and so it is difficult to judge their reactions towards the prey unless vomiting occurs after ingestion. A great tit 
handles the prey differently, often clipping off the wings before eating the butterfly and tearing the prey to pieces. If a great tit dislikes the taste it drops the prey, wipes its bill vigorously and sometimes goes to find water.

We mist-netted great tits with the permission of the North Savo Regional Environmental Center (0699L0420-254) during October and November in 1999. The great tits were housed individually under a $12 \mathrm{~h} / 12 \mathrm{~h}$ light/dark photoperiod and maintained on a diet of peanuts and sunflower seeds. After the experiment, these birds were released at the same location from which they were captured.

The palatability of P. napi and A. cardamines were compared to Leptidea sinapis that also belongs to Pieridae family. In a preliminary test (unpublished data), L. sinapis was offered to pied flycatchers and great tits, and the birds did not hesitate to attack or to eat them. The acceptability of $L$. sinapis was also verified in the last experiment of this study (see below.)

Butterflies were collected from the field in the summer and stored in the freezer until needed. We measured the comparative palatability of $P$. napi and $A$. cardamines by presenting them to wild-caught great tits in an experimental cage. In addition to these species we also tested the palatability of $P$. brassicae.

Since we used wild birds, refusal could be based on a bird's previous experience. A bird might have encountered an aposematic prey, tasted it, and found it unsuitable as food. To make the visual recognition and thus sight-rejection by the bird impossible, we glued the butterflies between two pieces of paper. Before the experiment the birds were trained to open similar prey items containing almond in four steps. After they had eaten a crushed almond, a piece of almond was glued to a small piece of paper. In the next steps the almond was partially visible between two pieces of paper and finally totally hidden between the pieces of paper. To ensure that the birds did not have difficulties in handling the prey, they were given 15 brown artificial almond prey items before the start of the experiment.

Because other butterflies were about twice the size of L. sinapis, they were cut vertically into two equal parts. The wings were cut up, and all the parts were glued between two pieces of paper. The wings were included in the prey because deterrents in butterflies can be unevenly distributed (Marsh and Rothschild, 1974). The sexes were tested separately because of sexual dimorphism in the concentration of unpalatable substances in some butterflies (Marsh and Rothschild, 1974, and references therein).

The birds were deprived of the food for two hours before the experiment. Their motivation was tested at the beginning of the experiment by giving them an almond prey; if the bird readily attacked the prey then it was considered to be ready for the test. The bird was then sequentially offered a wood white (L. sinapis) followed by two almond prey items and then a test butterfly (P. napi, A. cardamines, or P. brassicae). Each bird was offered only one species. If a 
bird considered the taste of the prey too nasty it could subsequently refuse to eat anything. To counteract this possible de-motivation effect of an unpalatable prey, two almond prey items were given to the bird. At the end of the experiment, $P$. napi soaked in $6 \%$ chloroquinine, which tits consider unpalatable, was offered to look for possible differences among individuals towards unpalatability. The experiments were recorded on videotape and the behaviour of each bird was analysed from these recordings. Behaviour indicating distaste (beak wiping, head shaking, and drinking) of the butterfly being eaten was recorded during prey handling and for $30 \mathrm{~s}$ after the prey had been dropped.

\section{The experiment with free-flying Pieridae}

To assess the birds' reactions towards live Pieridae, freely moving butterflies were presented singly to pied flycatchers $(n=23$; permit 0900L0254/254 from Central Finland Regional Environmental Center) at the beginning of June 2000. We had four outdoor cages (floor area: $3 \times 3 \mathrm{~m}$; height: $2 \mathrm{~m}$ ), each divided into three compartments, which allowed us to follow three birds simultaneously. After a bird had experienced $1 \mathrm{hr}$ food-deprivation, fieldcaught $L$. sinapis $(n=23), P$. napi $(n=23)$, and male $A$. cardamines $(n=21)$ were released singly in a random order into the outdoor cages. Birds were given an hour to catch each butterfly. We made observations through binoculars form a distance. We recorded whether the butterfly was attacked, whether it was eaten or rejected by the bird, or whether the butterfly was able to escape a bird's attack.

\section{Results}

\section{Preference experiment}

To compare the relative acceptabilities of $P$. napi and A. cardamines, they were presented to pied flycatchers $(n=20)$ alongside two other palatable butterfly species. Six birds ate all (i.e. 6) butterflies presented and five ate four or five butterflies. The average time ( \pm SE) between the first and last butterfly eaten was $20 \mathrm{~min} 47 \mathrm{~s}( \pm 236 \mathrm{~s})$. The average time for the consumption of the last butterfly was $30 \mathrm{~min} 3 \mathrm{~s}( \pm 305 \mathrm{~s})$. Birds did not show any clear preference difference (Friedman test $\mathrm{df}=5, p=0.079$ ) (Fig. 1). Because the preference ranks of male and female $P$. napi did not differ significantly (Wilcoxon signed ranks test: $z=-0.912 ; p=0.362$ ), we combined the data from both sexes for statistical tests. Likewise, control species were also combined to enhance the statistical power since their preference ranks did not differ (Wilcoxon signed ranks test: $z=-0.700 ; p=0.484$ ). When we compared the ranks of male and 


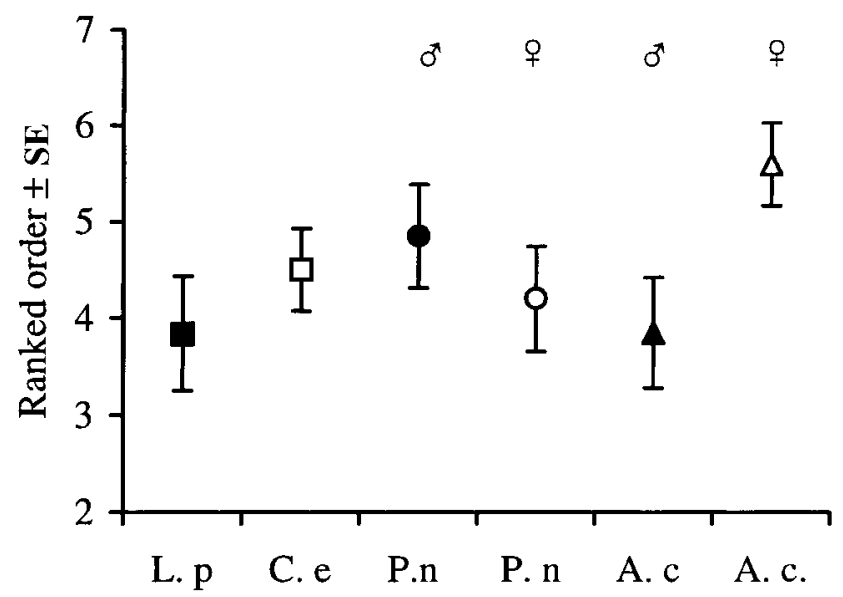

Figure 1. The ranked order of consumption of L. petropolitana (L.p), C. euphorosyne (C.e), P. napi (P.n), and $A$. cardamines (A.c) in the preference experiment $(n=20)$. The smaller the rank order is, the earlier the butterfly was consumed.

female $A$. cardamines, of $P$. napi and of control butterflies, birds ranked these groups differently (Friedman test: $\mathrm{df}=3 ; p=0.043$ ). There was a tendency for birds to least prefer female $A$. cardamines compared to other prey types (Table 1). When all Pieridae were lumped together and their mean rank compared to the mean rank of all control species we did not find significant difference in preference (Wilcoxon signed ranks test: $z=-0.808 ; p=0.419$ ). Even if we pooled only purely white butterflies ( $P$. napi and female $A$. cardamines) and compared their preference ranks to that of two control species and male A. cardamines (which have conspicuous orange tips on their forewings), we still did not find any statistical evidence that white coloration is less preferred among experienced predators (Wilcoxon ranks test: $z=-1.553 ; p=0.120$ ).

Table 1. Analyses of Wilcoxon signed ranks test for differences in the preference rank among species. Sequential Bonferroni corrected $p$-values in parenthesis

\begin{tabular}{|c|c|c|c|}
\hline & A. cardamines (ठิ) & A. cardamines (†) & Control species \\
\hline P. napi $(\hat{\jmath},+)$ & $\begin{array}{l}\mathrm{z}=-1.083 \\
p=0.279 \\
(p=0.837)\end{array}$ & $\begin{array}{l}\mathrm{z}=2.053 \\
p=0.040 \\
(p=0.240)\end{array}$ & $\begin{array}{l}\mathrm{z}=-0.602 \\
p=0.547 \\
(p=0.547)\end{array}$ \\
\hline A. cardamines (ठิ) & - & $\begin{array}{l}z=-2.024 \\
p=0.043 \\
(p=0.215)\end{array}$ & $\begin{array}{l}z=-0.667 \\
p=0.505 \\
(p=1.000)\end{array}$ \\
\hline 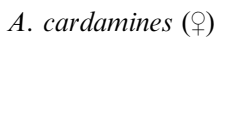 & - & - & $\begin{array}{l}z=-1.815 \\
p=0.070 \\
(p=0.280)\end{array}$ \\
\hline
\end{tabular}


Test for palatability in the laboratory

In the palatability test, $L$. sinapis were paired with $P$. napi $(n=18), A$. cardamines $(n=17)$, or P. brassicae $(n=9)$, and tests were separated by presentations of palatable almond prey. Head shaking and drinking never occurred. Thus, the beak wiping behaviour was used as the indicator of dislike behaviour (Fig. 2). The number of beak wipes was natural log transformed to meet the assumptions of repeated ANOVA. The birds did not vary in their dislike (number of beak wipes) of individuals from three Pieridae species $\left(F_{(2,43)}=0.851 ; p=0.435\right.$; number of beak wiping after consuming the unpalatable butterfly as covariate $\left.F_{(1,43)}=6.040 ; p=0.018\right)$. There was also no difference between L. sinapis and P. napi $\left(F_{(1,17)}=1.402 ; p=0.253\right)$, L. sinapis and A. cardamines $\left(F_{(1,16)}<0.001 ; p=0.990\right)$, or L sinapis and P. brassicae $\left(F_{(1,8)}=0.559 ; p=0.476\right)$. However, the responses to the test butterfly significantly differed from the behaviour triggered by the chloroquinine-flavoured butterfly $\left(P\right.$. napi vs. unpalatable $F_{(1,17)}=7.300 ; p=0.015 ; A$. cardamines vs. unpalatable $F_{(1,16)}=34.736 ; \quad p<0.001 ; \quad P$. brassicae vs. unpalatable $\left.F_{(1,8)}=8.068 ; p=0.022\right)$. These results indicate that birds did not find any species tested particularly unpalatable.

\section{The experiment with free-flying Pieridae}

Birds ate nearly all $L$. sinapis $(87 \%, n=23)$, while consuming roughly half of the $P$. napi $(48 \%, n=23)$ and $A$. cardamines $(67 \%, n=21)$. The difference is significant (Friedman test: $\mathrm{df}=2 ; p=0.025$ ). Leptidea sinapis was eaten more

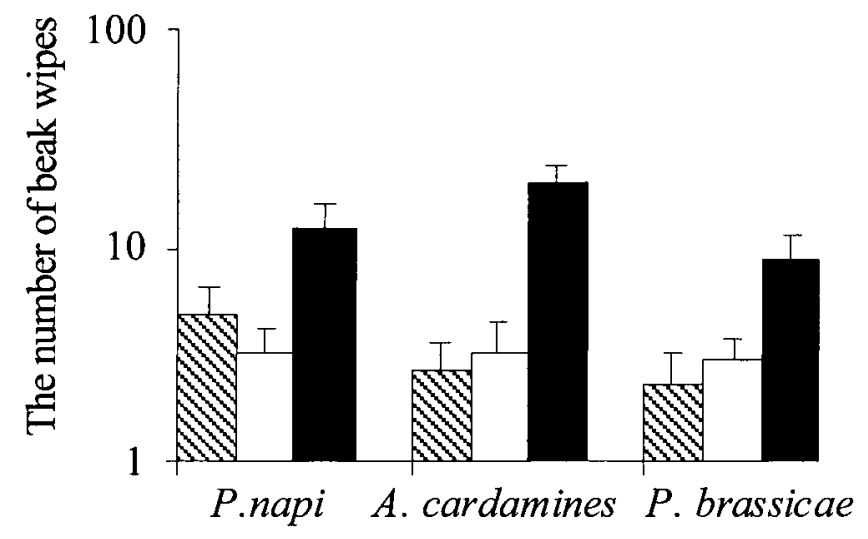

Figure 2. The graph shows the number of beak wipes for each butterfly tested: L. sinapis (the striped bars), $P$. napi (the first white bar, $n=18$ ), A. cardamines (the second white bar, $n=17$ ), $P$. brassicae (the third white bar, $n=9$ ), and chloroquinine-flavoured butterfly (the black bars). The result is divided into three groups according to which Pieridae butterfly was tested, which is indicated by the name under the $x$-axis. 
often than P. napi (Wilcoxon signed rank test: $z=-2.714 ; p=0.021$ after sequential Bonferroni correction) and there was a slight trend for L. sinapis to be more favourable prey than $A$. cardamines $(z=-2.000 ; p=0.092$ after sequential Bonferroni correction). The difference between $P$. napi and A. cardamines was insignificant $(z=-1.155 ; p=0.248)$.

We observed five cases when bird attacked $P$. napi but then rejected it. We suggest that these rejections might be due to the volatile odour of $P$. napi. We counted two successful escapes for $L$. sinapis, and four for $A$. cardamines. In addition, only one of the L. sinapis butterflies was not attacked by birds in contrast to seven $P$. napi and three A. cardamines.

\section{Discussion}

In the preference experiment, we did not find any clear evidence that the birds avoided Pieridae butterflies. The difference in preference between P. napi and $A$. cardamines was insignificant when they were presented alongside two non-aposematic alternative butterflies. Birds tended to consume the female A. cardamines last but the difference was statistically insignificant. A comparison between the mean rank of all Pieridae butterflies and the control butterflies failed to show that the Pieridae were less favoured prey. All butterflies were presented alive, placed on the tray, and thus only the appearance of the butterfly could affect the prey choice, not the behaviour. The result indicates that the white coloration, which is proposed to function as a warning signal, is not an efficient signal for the butterfly's potential unprofitability.

In addition, the palatability test did not show that the Pieridae butterflies presented in the study were unpalatable. Great tits did not show any difference in their dislike (shown by beak wiping, drinking etc.) of either P. napi or A. cardamines. Not even consumption of $P$. brassicae triggered any behaviours usually associated with eating unpalatable prey. Indeed, birds only showed their dislike of quinine-flavoured butterflies. The butterflies that were tested could not be classified as inedible according to the criteria we used or as being tremendously less palatable than L. sinapis. This conclusion is supported by the results from our experiment where free-flying butterflies were presented to birds in outdoor cages. Pieris napi and A. cardamines seemed to be palatable and only slightly less preferred than $L$. sinapis. Generally, all three species were eaten in at least $48 \%$ of the presentations. Chai et al. (1990) categorised a butterfly as unpalatable if the proportion of individuals eaten was less than $10 \%$ and as palatable if the proportion was $90-100 \%$. Species between these two extreme categories were defined as intermediate-palatable. On the basis of our results, both P. napi and A. cardamines could be put into this last category. 
The suitability of $L$. sinapis as a control species in the palatability experiment might be criticised since it belongs to the Pieridae family. However, the experiment with free-flying butterflies confirmed that it is indeed palatable to birds. Birds ate L. sinapis in almost every test and only a small proportion of them was unacceptable, and so we consider it to be a reasonable control species. The butterflies which were used in the palatability test were stored in a freezer, which might have changed their taste. There is a possibility that the freezing process might even have rendered unpalatable butterflies palatable. When we compare birds' reactions towards fresh, live butterflies to those towards frozen ones, we do not see any difference: neither frozen nor fresh butterflies elicited aversive behaviour in birds.

Taste is not the only feature that makes prey unprofitable. Fast speed and flight agility make a butterfly more difficult to capture. A butterfly can respond to an attack by changing its flight pattern to be more erratic and as a result a predator has difficulties in predicting the flight path of the prey (Humphries and Driver, 1967, 1970). The unpredictably disorients the predator and reduces the effectiveness of an attack. If a predator recognises the prey to be too difficult to catch it might give up capture attempts altogether (Gibson, 1974). On the other hand, slow flight can be linked with unpalatability: distasteful butterflies often have slower and less erratic flight than palatable species (Chai and Srygley, 1990; Srygley and Dudley, 1993; Pinheiro, 1996).

Other features affecting prey choice by birds are prey size and the body mass to wing ratio (Ley and Watt, 1989; but see Srygley and Kingsolver, 1998). In the preference experiment, the birds could not use the size of the butterfly or the flight patterns as a cue for unprofitablility because the butterflies were glued on the tray with open wings. Even if this might induce some risk of misidentification by birds, the set-up allowed us to evaluate the importance of white coloration per se as an anti-predator mechanism. On the other hand, the experiment in outdoor cages, which can be considered as a more natural situation, found some indication of avoidance towards free-flying $P$. napi and $A$. cardamines. Mortality of $P$. napi was lowest among the three species tested. It remains unclear as to what was the main reason for these observed differences. In some cases, a bird's attack probably failed due to the escape flight of the butterfly, but generally butterflies sat on the netting of the cages.

We also observed unsuccessful attacks where a bird captured $P$. napi by its wings but released it almost immediately, leaving the escaped butterflies seemingly unharmed. One possible reasons for these escapes might be the presence of a volatile odour in the wings. When a butterfly is touched it releases citric odour that could cause rejection by a bird. Two main compounds of the scale scent substances are neral and geranial (Hayashi et al., 1978); their function in $P$. napi is unknown. There is evidence that some distinctive odours can function as warning signals (Guilford et al., 1987), enhance avoidance 
learning (Roper and Marples, 1997), and elicit a bias against colours typically associated with aposematism (Rowe and Guilford, 1996, 1999). It has not been investigated whether volatile odours occur in $A$. cardamines but they seemed odourless to us. The alternative or additional strategies to avoid predation in $A$. cardamines could be the cryptic underside of its hindwings. In flight $A$. cardamines is conspicuous but when the butterfly rests with closed wings it blends into the vegetation and thus could escape detection by predators. The more yellow ventra of other Pieridae butterflies might also enhance crypsis but $A$. cardamines has a particularly camouflaged underside.

It is impossible to conclude that $P$. napi and $A$. cardamines are inedible because both species proved to be acceptable to the birds in our experiments. Furthermore, there is previous evidence for predation on P. napi (Dennis, 1993) and that it is palatable to Canada jays (Perisoreus canadensis) (Ley and Watt, 1989). The results of our experiments even also suggest that $P$. brassicae would not be as unpalatable as it has been previously claimed (Marsh and Rothschild, 1974). In fact, our birds found this species palatable. Although we did not find any strong indication of unpalatability in the Pieridae butterflies we tested or acceptability differences among them, it is not impossible that they could be Batesian or Müllerian mimics. Other characteristics, such as agility and fast flight speed or low nutritious contents, could render them unprofitable to avian predators compared to alternative prey. Indirect evidence for this possibility could be seen in the lower mortality of $P$. napi and A. cardamines compared to $L$. sinapis when butterflies were able to move more naturally in large outdoor cages and thus express all their signals to bird predators. All these facts suggest that $P$. napi and A. cardamines might be unprofitable prey but definitely not unpalatable to avian predator.

\section{Acknowledgements}

We thank the participants at the workshop, 'Aposematism - Past, present and future' for their helpful comments. We would also like to thank M. Halonen, J. Kilpimaa, and H. Siitari for their help in catching the birds. Special thanks to H. Nisu, who took care of our birds. Candy Rowe kindly corrected the language. The Academy of Finland financed the project.

\section{References}

Alatalo, R.V. and Alatalo, R.H. (1979) Resource partitioning among a flycatcher guild in Finland. Oikos 33, 46-54. 
Aplin, R.T., d'Arcy Ward, R. and Rothschild, M. (1975) Examination of the large white and small white butterflies (Pieris spp.) for the presence of mustard oils and mustard oil glycosides. J. Ent. (A) 50, 73-78.

Brower, L.P. (1984) Chemical defence in butterflies. In R.I. Vane-Wright and P.R. Ackery (eds) The Biology of Butterflies, Academic Press, London, pp. 109-134.

Chai, P. and Srygley, R.B. (1990) Predation and the flight, morphology, and temperature of Neotropical rainforest butterflies. Am. Nat. 135, 748-765.

Dennis, R.L.H. (1993) Predation in a northern population of Pieris napi (L.) (Lepidoptera: Pieridae): evidence from wing remnants. Entomol. Gaz. 44, 157-159.

Gibson, D.O. (1974) Batesian mimicry without distastefulness. Nature 250, 77-79.

Guilford, T., Nicol, C., Rothschild, M. and More, B.P. (1987) The biological role of pyrazines: evidence of a warning odour function. Biol. J. Linn. Soc. 31, 113-128.

Hiyashi, N., Kuwahara, Y. and Komae, H. (1978) The scent substances of male Pieris butterflies (Pieris melete and Pieris napi). Experientia 34, 684-685.

Humphries, D.A. and Driver, P.M. (1967) Erratic display as a device against predators. Science 156, 1767-1768.

Humphries, D.A. (1970) Protean defence by prey animals. Oecologia 5, 285-302.

Jones, F.M. (1932) Insect coloration and the relative acceptability of insects to birds. Trans. R. Ent. Soc. London 80, 345-385.

Kettlewell, H.B.D. (1965) Insect survival and selection for pattern. Science 14, 1290-1296.

Kingsolver, J.G. (1987) Predation, thermoregulation, and wing color in pierid butterflies. Oecologia 73, 301-306.

Lane, C. (1957) Preliminary note on insects eaten and rejected by a tame shama (Kittacincla malabarica GM.) with the suggestion that in certain species of butterflies and moths females are less palatable than males. Entomologist's Mon. Mag. 93, 172-179.

Ley, C. and Watt, W.B. (1989) Testing the 'mimicry' explanation for the Colias 'alba' polymorphism: palatability of Colias and other butterflies to wild bird predators. Funct. Ecol. 3, 183-192.

Marsh, N. and Rothschild, M. (1974) Aposematic and cryptic Lepidoptera tested on the mouse. J. Zool. Lond. 174, 89-122.

Marttila, O., Haahtela, T., Aarnio, H. and Ojanen, P. (1990) Suomen Päiväperhoset. Kirjayhtymä Oy, Helsinki, 362 pp.

Pinheiro, C.E.G. (1996) Palatability and escaping ability in Neotropical butterflies: tests with wild kingbirds (Tyrannus melancholicus, Tyrannidae). Biol. J. Linn. Soc. 59: 351-365.

Roper, T.J. and Marples, N.M. (1997) Odour and colour as cues for taste-avoidance learning in domestic chicks. Anim. Behav. 53, 1241-1250.

Rowe, C. and Guilford, T. (1996) Hidden colour aversions of domestic chicks triggered by pyrazine odours of insect warning displays. Nature 383, 520-522.

Rowe, C. and Guilford, T. (1999) Novelty effects in a multimodal warning signal. Anim. Behav. 57, $341-346$.

Srygley, R.B. and Chai, P. (1990) Flight morphology of Neotropical butterflies palatability and distribution of mass to the thorax and abdomen. Oecologia 84, 491-499.

Srygley, R.B. and Dudley, R. (1993) Correlations of the position of center of body mass with butterfly escape tactics. J. Exp. Biol. 174, 155-166.

Srygley, R.B. and Kingsolver, J.G. (1998) Red-wing blackbird reproductive behaviour and the palatability, flight performance, and morphology of temperate pierid butterflies (Colias, Pieris, and Pontia). Biol. J. Linn. Soc. 64, 41-55. 
